\title{
RECENT LABORATORY PHOTOCHEMICAL STUDIES AND THEIR RELATIONSHIP TO THE PHOTOCHEMICAL FORMATION OF COMETARY RADICALS
}

\author{
WILLIAM M. JACKSON \\ Department of Chemistry \\ University of California \\ Davis, California 95616 \\ United States of America
}

\begin{abstract}
Experimental laboratory techniques used in studying the photochemistry of stable and unstable molecules are discussed. The laboratory evidence for the photochemical formation of $\mathrm{C}_{2}$ from $\mathrm{C}_{2} \mathrm{H}, \mathrm{C}_{3}$ from $\mathrm{C}_{3} \mathrm{H}_{2}$, and $\mathrm{NH}$ from $\mathrm{NH}_{2}$ is presented. Other recent results obtained in laboratory studies of $\mathrm{H}_{2} \mathrm{O}, \mathrm{H}_{2} \mathrm{~S}, \mathrm{NH}_{3}$, and $\mathrm{HCN}$ are reported.
\end{abstract}

\section{Introduction}

The chemistry of comets is dominated by photochemistry (Wurm 1943, Mendis and Houpis 1982), so it is natural that a review of laboratory studies as they relate to comets should also be dominated by photochemistry. Most of the cometary photochemistry occurs under conditions that are very different from the typical conditions used for laboratory photochemical studies. In comets, the photochemical light source is the Sun, with a broad spectral distribution that extends from $300 \mathrm{~nm}$ to $140 \mathrm{~nm}$, with a secondary peak at $121.6 \mathrm{~nm}$ (Huebner and Carpenter 1979). The density of the gas is low enough that there is a long time between collisions even in the collision regime of the coma, and a large portion of the photochemistry occurs in the collisionless region of the coma. Secondary photolysis of primary products can and often does occur in comets (Cochran 1985, O'Dell et al. 1988), while in the laboratory, attempts are generally made to minimize this. A comet's conditions, of course, cannot really be duplicated in the laboratory, so it is important that systematic laboratory studies of the important molecules are done so the results can be intelligently applied to comets. This is a formidable task because of the wide spectral range that must be covered, the transitory existence of some of the molecules, e.g., free radicals, that must be studied, and the unique internal energies of these molecules. Every modern tool of the photochemist, including lasers and molecular beams, is required to address this problem. Fortunately, there has been a tremendous increase in the 
experimental arsenal of the photochemist in recent years, and some of the important questions can now be answered. In this short review, not all of the detailed knowledge about photochemistry that has been recently obtained can be covered, but many good reviews are available (Ashfold and Baggott 1987, Ashfold et al. 1979, Jackson and Okabe 1986, Leone 1982, Okabe 1978, Royal Society of Chemistry 1986, Sato 1986). Instead, the key areas that apply to comets will be identified and discussed with a special emphasis on how the experiments and their theoretical interpretations can be used to enhance our understanding of the chemistry of comets.

Despite the fact there is general agreement that photochemistry is the most important source of radicals in comets, there have been other models that include ion-molecule reactions (Mendis and Houpis 1982). These models explain some of the ions, but are unlikely to explain most of the neutrals (Mendis and Houpis 1982). One problem all of these models have is accounting for the low-density fluid flow of the gas. Supersonic expansion of the gas develops within a few hundred kilometers of the nucleus. Once this happens, unless outside forces intervene, the molecules will not have a component of velocity perpendicular to the flow that is large enough to maintain collisions. It is analogous to two boats moving in a fast flowing river - they will never collide unless there is some turbulence, a rock, etc. The outside forces acting on the molecules flowing in comets are solar photolysis and the solar wind, both of which take time to affect the gas. When these outside forces finally couple to the gas, the density should be low enough that most molecules will undergo only a few collisions.

In the balance of this review, the new experimental techniques of photochemistry will be summarized briefly. This summary will be followed by a discussion of the use of these techniques to study the fundamental photochemical processes that can lead to the formation of cometary radicals such as $\mathrm{C}_{2}, \mathrm{C}_{3}, \mathrm{NH}, \mathrm{CN}$, and $\mathrm{SH}$.

\section{New Experimental Techniques}

\subsection{TIME-OF-FLIGHT (TOF) PHOTOFRAGMENT SPECTROSCOPY}

The most universal technique for the study of photochemistry is the TOF photofragment spectroscopic technique. This technique combines the wavelength specificity of lasers with molecular beams and the universal detection technique of mass spectrometry. In its most elegant form, the TOF analysis is done as a function of angle so that a momentum balance may be obtained for the two fragments (Wodtke and Lee 1987). From this information, the center-of-mass recoil velocity vectors can be obtained, which then define the amount of internal energy remaining in the fragments. The method requires a fairly intense laser light and a mass spectrometer with a very low background pressure. With this method, however, certain generalizations are possible about the photodissociation process. Molecules that undergo statistical types of dissociation such as predissociation and internal conversion generally release very little of the available energy to the translational degrees of freedom. Molecules that undergo direct dissociation or predissociation into molecular fragments release a great deal of the available energy into the translational recoil motion. The first generalization can be understood in terms of unimolecular reaction theory. Molecules that undergo indirect dissociation and internal conversion will tend to randomize the excitation energy into the internal degrees of 
freedom, resulting in the highest probability for dissociation to occur near the energy threshold for the process. As a result, most of the fragments will have very little translational energy and more internal energy.

In direct dissociation, the excited molecule is produced on the repulsive part of an excited potential energy surface, which is significantly above the dissociation limit. Hence, the fragments are produced with large amounts of translational energy. Predissociation into molecular fragments generally requires the excited molecule to overcome an energy barrier in the potential energy surface before it can rearrange itself into stable molecular fragments. The barrier is generally higher than the threshold energy for dissociation, which results in large amounts of translational recoil energy.

The basic disadvantage of this method is its requirement for an intense laser light source. This means that it is difficult to study the effects of energy on the dissociation process, which is particularly important for comets. The situation is further complicated by the fact that the most important wavelength region for comets is below $200 \mathrm{~nm}$ where there are few strong laser sources. As more intense vacuum ultraviolet (VUV) laser sources or new sources such as the Advanced Synchrotron Light Source become available, this technique will be increasingly important for cometary studies. Already, as the discussion on the formation of $\mathrm{C}_{2}$ and $\mathrm{C}_{3}$ will show, some of the results that have been obtained with this technique can be used to provide key information about some important cometary molecules.

\subsection{LASER-INDUCED FLUORESCENCE (LIF) STUDIES}

The detection of photochemical fragments using the LIF method has been one of the most successful experimental techniques used in photochemistry (Jackson 1973, Jackson and Cody 1974). This technique has great sensitivity and can be used to detect and identify very low concentrations of fragments formed during photodissociation. The internal energy of the fragments can be characterized, and in favorable cases, the recoil velocity can be measured by determining the Doppler profile of the line. Polarized lasers can be employed to investigate the alignment of fragments during photodissociation, which in turn provides information about the symmetry of the excited states of the parent molecules used to produce the fragments. The use of polarized lasers for both dissociation and characterization can also provide information about the correlation between the recoil velocity vector, $v$, the electronic transition dipole vector, $\mu$, and the angular momentum vector, J.

The LIF method does have its limitations, despite the wonderful information that can be obtained when it is used. It can only be used for fragments that emit light after being excited to the excited state by the laser. This is less of a problem for cometary science than it is for chemistry in general, because some of the most important cometary fragments-e.g., $\mathrm{CH}, \mathrm{C}_{2}, \mathrm{OH}, \mathrm{H}, \mathrm{C}, \mathrm{O}, \mathrm{C}_{3}, \mathrm{NH}_{2}, \mathrm{CO}^{+}, \mathrm{N}_{2}{ }^{+}, \mathrm{S}_{2}$, and $\mathrm{CS}$-meet this criteria. It is often difficult to analyze a nascent radical spectrum, i.e., one obtained before collisions, because of the complexity of the spectrum when the molecules are rotationally and vibrationally excited. A spectrum can also be complex because of perturbations from other excited states, while another may be complex because the internuclear axis changes between the ground and excited state, resulting in its being spread over thousands of angstroms. The CS molecule is an example of the former case, while the $\mathrm{NH}_{2}$ radical is an example of the latter case. Finally, to obtain all of the information needed for comets, it is 
still important to determine the photochemistry at a variety of wavelengths, because the whole character of the photodissociation process may change within a few hundred angstroms.

\subsection{LASER IONIZATION TECHNIQUES}

There are several classes of ionization techniques that can be used to study the chemistry occurring during photodissociation. One of these is to use the multi-photon ionization technique to characterize those fragments that do not emit light. In this method, a visible laser is tuned to a wavelength that coincides with a single- or multi-photon resonance in the fragment. After exciting the fragment to the excited state, another photon is used to ionize the fragment. These ions may then be detected and characterized using some type of mass analysis such as a quadrupole or a time-of-flight mass spectrometer.

Another type of ionization technique that can be employed in photochemical studies is the single-photon ionization technique. This generally requires a laser in the VUV region of the spectrum that has enough energy to ionize the fragments. After ionization, the fragments may also be mass-analyzed so that they can be identified. If the laser is tunable, it is often possible to obtain information about the internal energy distribution of the fragments, if the rotational and vibrational states can be resolved.

Other variations on the ionization technique include photoelectron spectroscopy on the recoiling photoelectron. This can often be used to identify the intermediate fragments, as well as obtain information about their internal state.

Some of the same information that is obtained with the LIF method can be obtained with the ionization methods. Time-of-flight analysis can be used to determine the velocity distributions if complicating effects such as stray electric and magnetic fields and space charges can be accounted for or minimized.

Relative population measurements are often difficult to obtain using multi-photon ionization techniques, because of fluctuations in laser power and unknown multi-photon cross-sections. Similar problems can occur with the single photoionization techniques, because laser VUV light is generally obtained by a nonlinear process that reflects itself in large variations of laser intensity. Despite these difficulties, much important and useful information about photochemistry has been obtained using these methods.

\section{Recent Photochemical Results}

\section{1. $\mathrm{C}_{2}$ FORMATION}

Some time ago (Yamamoto 1981), it was suggested that the $\mathrm{C}_{2}$ radical was formed in comets by the following mechanism:

$\mathrm{C}_{2} \mathrm{H}_{2}+\mathrm{hv} \rightarrow \mathrm{C} \mathrm{C}_{2} \mathrm{H}+\mathrm{H}$
$\mathrm{C}_{2} \mathrm{H}+\mathrm{hv} \rightarrow \mathrm{C}_{2}+\mathrm{H}$

Analysis of the radial profiles from the $\mathrm{C}_{2}$ emission in comets (Cochran 1985, Jackson 1976, Yamamoto 1981) also suggests that a two-step photochemical mechanism is required. Very recent data of O'Dell et al. (1988) suggest that the $C_{2}$ emission can be 
caused by a three-step dissociation. If this is the case, it is not in accord with the present proposal. It will require a second intermediate radical other than $\mathrm{C}_{2} \mathrm{H}$, which in turn will mean that further laboratory work will be required.

Emissions from the radicals $\mathrm{C}_{2}\left(\mathrm{C}^{1} \Pi_{\mathrm{g}}\right)$ (McDonald et al. 1978), $\mathrm{C}_{2}\left(\mathrm{~d}^{3} \Pi_{\mathrm{g}}\right)$ (Craig et al. 1982, Jackson et al. 1978, Okabe 1975, Okabe et al. 1985), and $\mathrm{CH}\left(\mathrm{A}^{2} \Delta\right)$ (Craig et al. 1982, Jackson et al. 1978) have been observed during laboratory experiments of the 193-nm laser photolysis of acetylene. There is not enough energy in a single laser photon to produce these excited species, so they must have been produced by a multi-photon process. Both infrared (Fletcher and Leone 1989, Shokoohi et al. 1986) and broadband visible emissions (Ashfold et al. 1979, Becker et al. 1971, Saito et al. 1984, Stief et al. 1965 , Urdahl et al. 1988) from the vibrationally and electronically excited $\mathrm{C}_{2} \mathrm{H}$ radical have also been observed. Time-of-flight studies of the $\mathrm{C}_{2}$ and $\mathrm{C}_{2} \mathrm{H}$ fragments that are produced during the 193-nm photolysis of $\mathrm{C}_{2} \mathrm{H}_{2}$ have been performed (Wodtke and Lee 1983). These studies show the primary photochemical process to be the production of the $\mathrm{C}_{2} \mathrm{H}$ radical via the first reaction above. No evidence was found for the single-photon production of $\mathrm{H}_{2}$ and $\mathrm{C}_{2}$. Recently (Urdahl et al. 1988), LIF and time-resolved emission studies have shown that the yields of $C_{2}\left(A^{1} \Sigma_{\mathrm{u}}\right)$ and $\mathrm{C}_{2}\left(\mathrm{a}^{3} \Sigma_{\mathrm{u}}\right)$ are much greater than the yields of $\mathrm{C}_{2}\left(\mathrm{C}^{1} \Pi_{\mathrm{g}}\right)$ and $\mathrm{C}_{2}\left(\mathrm{~d}^{3} \Pi_{\mathrm{g}}\right)$ radicals. An example of the nascent LIF spectra obtained in these studies is shown in Figure 1. From the time-resolved emission, it was suggested that the $\mathrm{C}_{2}\left(\mathrm{~A}^{1} \Sigma_{\mathrm{u}}\right)$ and $\mathrm{C}_{2}\left(\mathrm{a}^{3} \Sigma_{\mathrm{u}}\right)$ radicals are formed from the same electronic state of $\mathrm{C}_{2} \mathrm{H}$. The $\mathrm{C}_{2}\left(\mathrm{X}^{1} \Sigma_{\mathrm{g}}{ }^{+}\right)$ground state has been probed by two-photon excitation to the $\mathrm{C}_{2}\left(\mathrm{C}^{1} \Pi_{\mathrm{g}}\right)$ state. The two-photon spectrum observed for $\mathrm{C}_{2}\left(\mathrm{X}^{1} \Sigma_{\mathrm{g}}{ }^{+}\right)$from this process is shown in Figure 2. This spectrum was only observed when the probe laser was delayed 10 microseconds after the photolysis laser, which indicates that the ground state of $C_{2}$ is probably being formed as a result of fluorescence from an excited state of the $C_{2}$ radical. We have recently used transient infrared spectroscopy to show that $C_{2}\left(b^{3} \Sigma_{g}^{-} g \rightarrow a^{3} \Pi_{u}\right)$ is also observed when $\mathrm{C}_{2} \mathrm{H}$ is photolyzed.

The postulate that $\mathrm{C}_{2}$ is formed from the photolysis of $\mathrm{C}_{2} \mathrm{H}$ was further checked by photolyzing $\mathrm{C}_{2} \mathrm{D}_{2}$ and $\mathrm{CF}_{3} \mathrm{C}_{2} \mathrm{H}$. As Figure 3 shows, in both cases, the Deslandresd'Azambuja could be excited using the LIF technique, indicating that the $\mathrm{C}_{2}$ molecule is being produced. The only common fragment in all three molecules is the $\mathrm{C}_{2} \mathrm{H}$ radical, which suggests that it is the source of the observed $\mathrm{C}_{2}$.

The nascent distributions obtained from the LIF measurements of the $\mathrm{C}_{2}$ fragments in the photodissociation of the above acetylene derivatives are illustrated in Figure 4 . The results indicate that there is very little difference between the observed distributions for the various molecules. All of them are Boltzmann-like in character, indicating that dissociation occurs via a statistical process. This in turn means that dissociation probably occurs via predissociation or internal conversion to the ground state continuum. In such a process, the nascent product state distributions may be calculated using a statistical theory such as phase space theory or the modified phase space theory of Wittig (Buelow et al. 1986). This is an extremely important result for cometary science because it means the dissociation of this free radical in this particular electronic state can be described using these theories as compared to more complex theories (Kresin and Lester 1986; Schinke 1988, 1989a, $1989 \mathrm{~b}$ ). As a result, if the spectroscopy and the electronic state of this radical are known, the photochemistry in this particular band could, in principle, be theoretically calculated.

The distributions in Figure 4 can be decomposed into two statistical distributions. One of these distributions can be characterized by a temperature below room temperature, 
(a)

The LIF Spectrum of $C_{2}$ Deslandres-d'Azambuja Band $\left(C^{1} \Pi_{g}-A^{1} \Pi_{u}\right)$

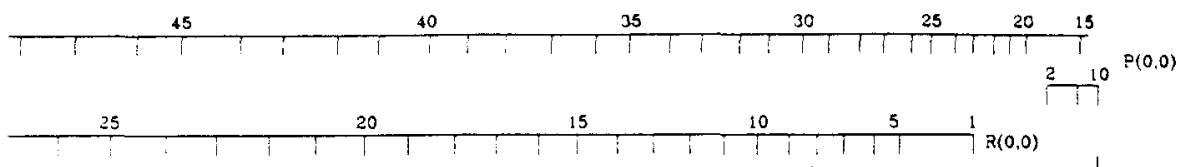

(b)

The LIF Spectrum of $C_{2}$ Swan Band $\left(d^{3} \Pi_{g}-a^{3} \Pi_{u}\right)$

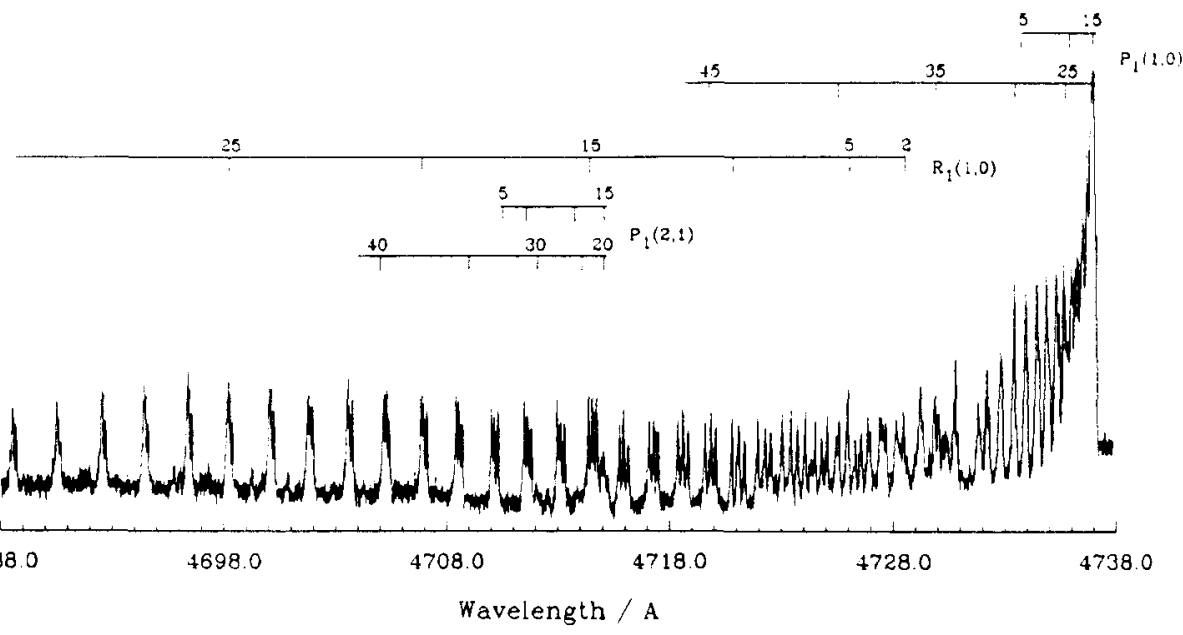

Figure 1. (a) The nascent $\mathrm{LIF} \mathrm{C}_{2}$ spectrum from the 193.3-nm photolysis of $\mathrm{C}_{2} \mathrm{H}$ produced in the 193.3-nm photolysis of $\mathrm{C}_{2} \mathrm{H}_{2}$. (b) The nascent $\mathrm{LIF}$ spectrum of the Swan system obtained from the photolysis of $\mathrm{C}_{2} \mathrm{H}$ formed in the $193-\mathrm{nm}$ photolysis of $\mathrm{C}_{2} \mathrm{H}_{2}$. 
The 2-Photon LWF Spectrum of $C_{2} C^{1} \Pi_{g}-x^{1} \Sigma_{g}^{+}$Band

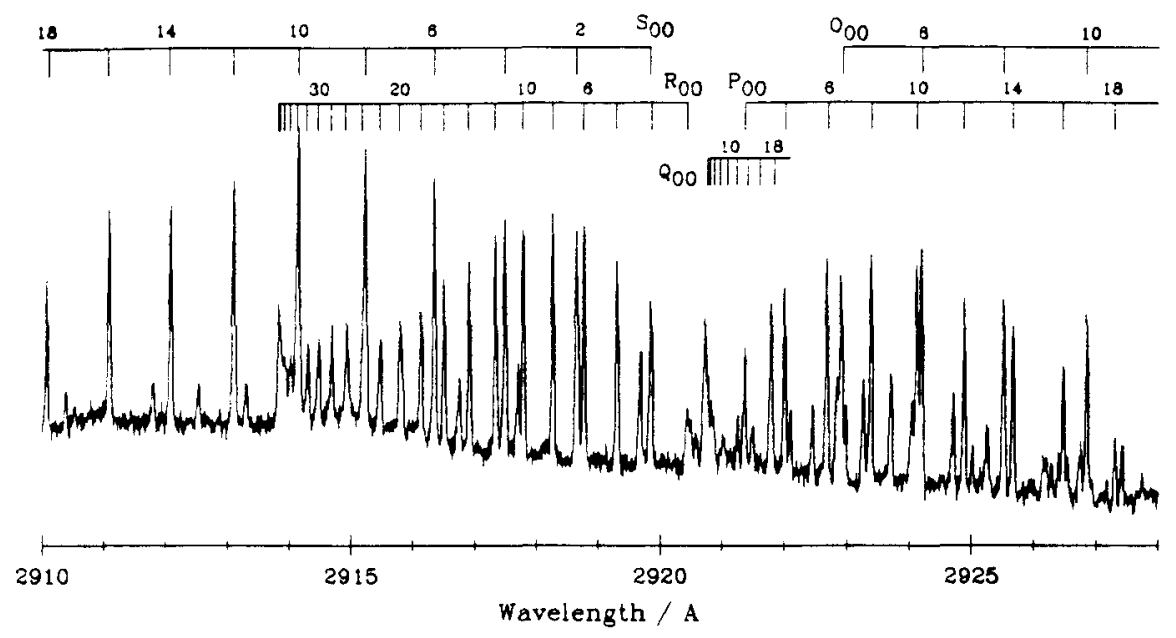

Figure 2. The two-photon spectrum of ground state $\mathrm{C}_{2}$ is observed only after a 10 microsecond delay, so it is not a nascent product.

and the other by a distribution above room temperature. There is very little change in either of these distributions when the source of the $\mathrm{C}_{2} \mathrm{H}$ radical is changed. In the case of the $\mathrm{CF}_{3}$ radical, the $\mathrm{C}-\mathrm{C}$ bond dissociation energy is smaller that it is in $\mathrm{C}_{2} \mathrm{H}_{2}$ or $\mathrm{C}_{2} \mathrm{D}_{2}$, yet the distributions are very similar. Such a result is understandable on the basis of a statistical theory, because most of the available energy comes when the second 193-nm photon is absorbed. A dynamical explanation of the results should exhibit a more drastic change as the masses change. If a $\mathrm{CF}_{3}$ radical recoils via a repulsive interaction from an excited $\mathrm{CF}_{3} \mathrm{C}_{2} \mathrm{H}$ molecule, the $\mathrm{C}_{2} \mathrm{H}$ radical could exhibit a lot of rotational excitation, which in turn should be reflected in the rotational excitation of the $\mathrm{C}_{2}$ radical. This is evidently not the case in either this molecule or in the $\mathrm{C}_{2} \mathrm{D}_{2}$ molecule, in agreement with the notion of a statistical dissociation in this absorption band.

The results described above depend upon the $\mathrm{C}_{2} \mathrm{H}$ radical being formed vibrationally excited, because the theoretical calculations of Shiu et al. (1979) indicate that a second photon does not have enough energy to excite a linear $\mathrm{C}_{2} \mathrm{H}$ fragment to an allowed excited state. However, in the bent configuration, the energy of the excited state that correlates to a $\mathrm{C}_{2}$ radical in the $\mathrm{A}^{2} \Sigma$ is decreased, so that it could be accessed by a second $193-n m$ photon. Further experiments are required using vibrationally cold $\mathrm{C}_{2} \mathrm{H}$ radicals to determine the wavelengths that can be used for dissociation. Vibrationally cold $\mathrm{C}_{2} \mathrm{H}$ radicals are the type of radicals that should be present in comets.

This example illustrates the synergistic relationship between theory, and TOF and LIF observations. It also illustrates how a systematic study using several molecules can help us understand the photochemistry of free radicals. 
(a)

$$
\mathrm{C}_{2} \mathrm{D}_{2}
$$

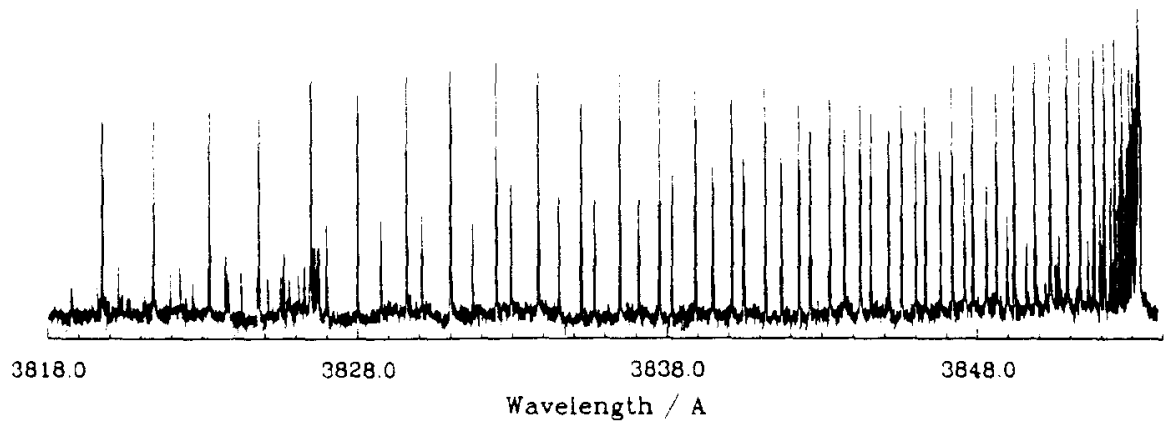

(b)

$$
\mathrm{CF}_{3} \mathrm{C}_{2} \mathrm{H}
$$

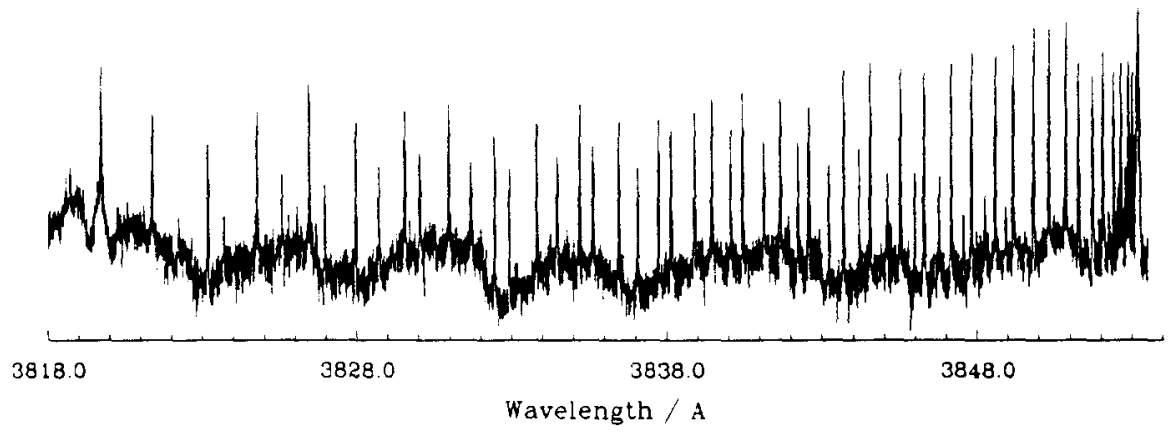

Figure 3. (a) The nascent LIF spectrum of $C_{2}$ of the $A^{1} \Sigma_{1}$ state formed in the 193.3-nm photolysis of $\mathrm{C}_{2} \mathrm{D}$ formed in the $193.3-\mathrm{nm}$ photolysis of $\mathrm{C}_{2} \mathrm{D}_{2}$. (b) The nascent LIF spectrum of $\mathrm{C}_{2}$ of the $\mathrm{A}^{1} \Sigma_{\mathrm{u}}$ state formed in the $193.3-\mathrm{nm}$ photolysis of $\mathrm{C}_{2} \mathrm{H}$ formed in the 193.3-nm photolysis of $\mathrm{CF}_{3} \mathrm{C}_{2} \mathrm{H}$. 
Rotational Energy Distribution for the $C_{2}\left(A^{1} \Pi_{u}, \nabla^{\prime \prime}=0\right)$ Fragment

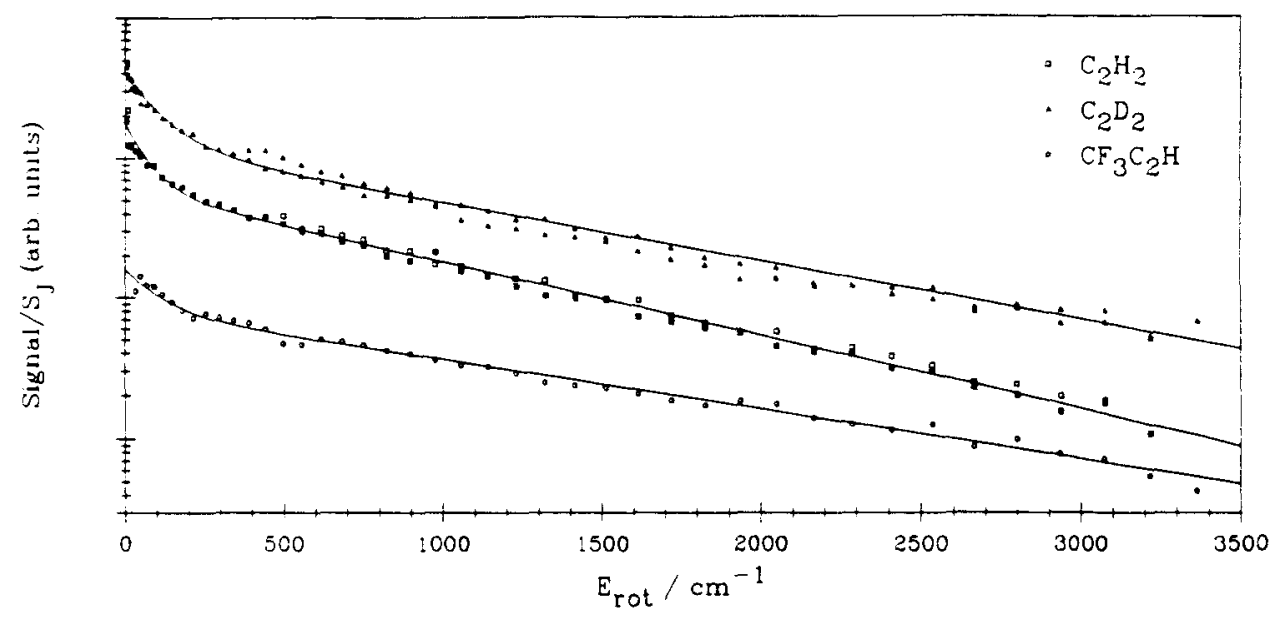

Figure 4. Rotational distributions obtained from the LIF spectrum shown in Figures 1(a) and 3.

It is interesting to compare the laboratory distribution with the rotationally resolved $\mathrm{C}_{2}$ distribution in the Swan bands obtained from comet Halley (Gredel et al. 1989). It is well-known that the observed rotational distribution of $\mathrm{C}_{2}$ in comets should be due to resonance fluorescence excitation from solar radiation. The observations suggest that the rotational temperature is lower on the nucleus that it is off the nucleus. It has been suggested that this may be due to shielding of the solar radiation in the inner portion of the coma of the comet by dust. O'Dell et al. (1988) have argued that this is not the case. An alternate explanation is that the nucleus observations have a higher fraction of $\mathrm{C}_{2}$ radicals that have not undergone many fluorescent cycles and thus are reflective of the rotational distributions originally produced as a result of the photodissociation process that produces the $\mathrm{C}_{2}$ radical. The $\mathrm{C}_{2}$ radical should be particularly sensitive to this, since it is a homonuclear molecule and it will not undergo pure rotational and vibrational transitions in the infrared region. Thus, it will lose its original rotational distribution only by many successive electronic transitions. Clearly, the nucleus spectra will have the highest number of radicals that have undergone the least number of electronic transitions.

\section{2. $C_{3}$ FORMATION}

The problem of $\mathrm{C}_{3}$ formation in comets has also attracted the attention of cometary scientists for years (Marsden 1974). In comets, emission from the $C_{3}$ radical is observed before emission from the $\mathrm{C}_{2}$ radicals as the comet approaches the Sun (Delsemme 1975, Marsden 1974). This radical is probably formed as a result of secondary photolysis of a primary photolytic product, because laboratory investigations indicate that there are no 
likely parent molecules that could produce these radicals in a single photochemical step (Jackson 1976, 1982; Payne and Stief 1972). The experiments described above provided firm evidence for the production of $\mathrm{C}_{2}$ radicals from the photolysis of $\mathrm{C}_{2} \mathrm{H}$ during the highintensity photolysis of $\mathrm{C}_{2} \mathrm{H}_{2}$. Yet there have been no reports of similar evidence for the $\mathrm{C}_{3}$ radical. In this section, the results of new experiments will be presented that provide direct confirmation for the production of $\mathrm{C}_{3}$ via the secondary photolysis of the $\mathrm{C}_{3} \mathrm{H}_{2}$ radical. The results of these experiments, along with the results of previous experiments, will be discussed in terms of their cometary implications.

The allene molecule, $\mathrm{C}_{3} \mathrm{H}_{4}$, was chosen as a likely candidate for a parent molecule that may photodecompose to a $\mathrm{C}_{3} \mathrm{H}_{\mathrm{x}}$ intermediate, which in turn could absorb a photon to produce the $\mathrm{C}_{3}$ radical. Earlier infrared (IR) diode laser absorption studies had indicated that this radical is present in a system in which allene is photolyzed with an ArF laser at $193 \mathrm{~nm}$ (Matsumura et al. 1988). The conditions under which these experiments were performed did not permit the determination of the photochemistry occurring in the system.

The absorption spectrum of allene (Rabalais et al. 1971) extends up to $260 \mathrm{~nm}$, which means that it overlaps the strong ultraviolet (UV) solar spectrum and suggests this molecule may have a short photochemical lifetime. This is certainly desirable if the $\mathrm{C}_{3}$ radical is to be produced in comets by the photolysis of a radical produced in the initial photolysis of $\mathrm{C}_{2} \mathrm{H}_{4}$.

Time-of-flight experiments were performed using two different molecular beam machines. One of these machines is a rotating source machine (RSM), which was specifically designed for photochemical studies (Wodtke and Lee 1987), and was used to detect fragments with masses from $\mathrm{m} / \mathrm{e}=12$ to 39 . In the RSM, the allene is seeded in a He carrier gas, and it has a beam velocity of $2 \times 10^{5} \mathrm{~cm} / \mathrm{s}$. The other beam machine that was used was optimized for the detection of $\mathrm{H}$ and $\mathrm{H}_{2}$ (Continetti 1989), and it employs an unseeded pulsed molecular beam of pure allene. The speed of this beam is about $8 \times 10^{4} \mathrm{~cm} / \mathrm{s}$, and this machine is designated as the hydrogen beam machine (HBM).

In the RSM, fragment ions with $\mathrm{m} / \mathrm{e}^{\prime} \mathrm{s}=39,38,37,36$, and 26 are observed at scattering angles from $7^{\circ}$ to $30^{\circ}$. No mass 40 is observed at these angles, proving that the radicals that are observed are not the result of photofragmentation of dimers. A typical set of TOF spectra for masses $39,38,37,36$, and 26 that were obtained in these experiments is shown in Figures $5,6,7,8$, and 9.

The observation of mass 39 unequivocally shows that the $\mathrm{C}_{3} \mathrm{H}_{3}$ radical is formed as a primary reaction product in the photolysis of allene. Masses $38,37,36$, and 26 could have all been due to dissociative ionization of this $\mathrm{C}_{3} \mathrm{H}_{3}$ fragment in the mass spectrometer ionizer, but the angular distributions of the TOF spectra showed that each of these masses had an additional component due to a new neutral fragment. The identity of these neutral fragments was determined by fitting the TOF measurements at the various angles. These fits were accomplished by using the forward convolution technique that has been described previously (Zhao 1988). The solid curve is the result of the fits with this forward convolution technique. It is made up of time-of-flight curves of the fragments from the following primary and secondary photochemical reactions:

$$
\begin{aligned}
\mathrm{C}_{3} \mathrm{H}_{4}+\mathrm{hv} & \rightarrow \mathrm{C}_{3} \mathrm{H}_{2}+\mathrm{H}_{2} \\
& \rightarrow \mathrm{C}_{3} \mathrm{H}_{3}+\mathrm{H}
\end{aligned}
$$


Time of Flight Spectra for $\mathrm{m} / \mathrm{e}=39$ at $\theta=10^{\circ}$

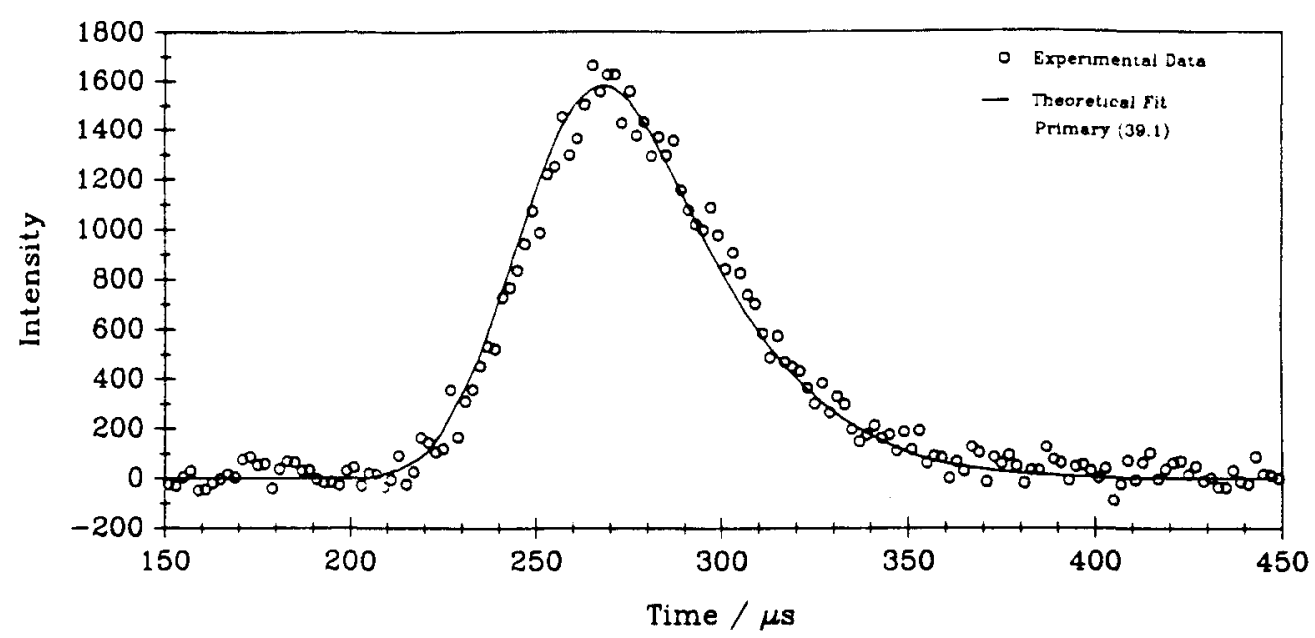

Figure 5. TOF spectrum from the 193.3-nm photolysis of $\mathrm{C}_{3} \mathrm{H}_{4}$. The theoretical fit is obtained using only one primary channel that produces $\mathrm{C}_{3} \mathrm{H}_{3}$ and $\mathrm{H}$.

$\begin{array}{rlll}\mathrm{C}_{3} \mathrm{H}_{3}+\mathrm{hv} & \rightarrow & \mathrm{C}_{2} \mathrm{H}_{2}+ & \mathrm{CH} \\ & \rightarrow & \mathrm{C}_{3} \mathrm{H}_{2}+ & \mathrm{H} \\ \mathrm{C}_{3} \mathrm{H}_{2}+\mathrm{hv} & \rightarrow & \mathrm{C}_{3} \mathrm{H}+ & \mathrm{H}_{2} \\ & \rightarrow & \mathrm{C}_{3} \mathrm{H}+ & \mathrm{H} \\ & & \rightarrow & \mathrm{C}_{3}+\end{array}$

A fit was considered successful only if the derived translational energy distribution would fit both fragments at all of the observed laboratory angles. This means, e.g., the same translational energy distribution must be able to fit the data for mass 26 and mass 13 in reaction 3. The translational energy distributions for reactions $1,2,4,5,6$, and 7 also fit the mass 1 and 2 time-of-flight spectra.

The translational energy distributions derived from these fits are given in Figure 10. Reaction 2 leads to the formation of a $\mathrm{H}$ atom and $\mathrm{C}_{3} \mathrm{H}_{3}$, and the translational energy distribution is peaked at low translational energies with a long exponential tail. The shape of the translational energy curve for the $\mathrm{H}$ atom in Reaction 4 is the same, but it has been shifted out to larger energies. A $\mathrm{H}$ atom is also produced in Reaction 6 , and it has a $\mathrm{P}\left(\mathrm{E}_{\mathrm{T}}\right)$ that is very similar to the translational energy curve for Reaction 4 . This systematic shifting of the $\mathrm{P}\left(\mathrm{E}_{\mathrm{T}}\right)$ to higher energies, when the fragment absorbs a second photon, is also apparent in the $\mathrm{H}_{2}$ channels, as a comparison of the $\mathrm{P}\left(\mathrm{E}_{\mathrm{T}}\right)$ for Reactions 1,5 , and 7 shows. In this case, however, the initial $\mathrm{P}\left(\mathrm{E}_{\mathrm{T}}\right)$ for the first fragment via Reaction 1 starts out at higher energies. The reaction that produces the $\mathrm{CH}$ radical and the $\mathrm{C}_{2} \mathrm{H}_{2}$ molecule is also peaked at low energies, which is consistent with its being a free-radical elimination 
Time of Flight Spectra for $\mathrm{m} / \mathrm{e}=38$ at $\theta=20^{\circ}$

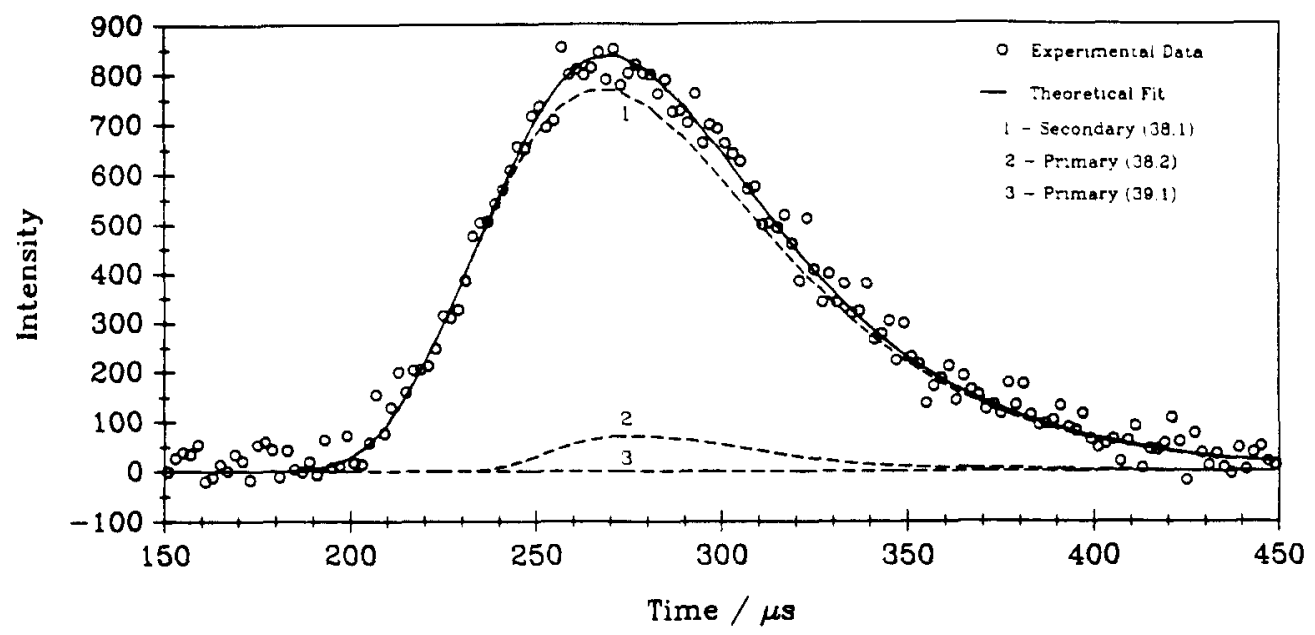

Figure 6. TOF spectrum from the $193-\mathrm{nm}$ photolysis of $\mathrm{C}_{3} \mathrm{H}_{4}$. Three channels are needed for the theoretical fit: two primary channels and one secondary channel.

Time of Flight Spectra for $\mathrm{m} / \mathrm{e}=37$ at $\theta=20^{\circ}$

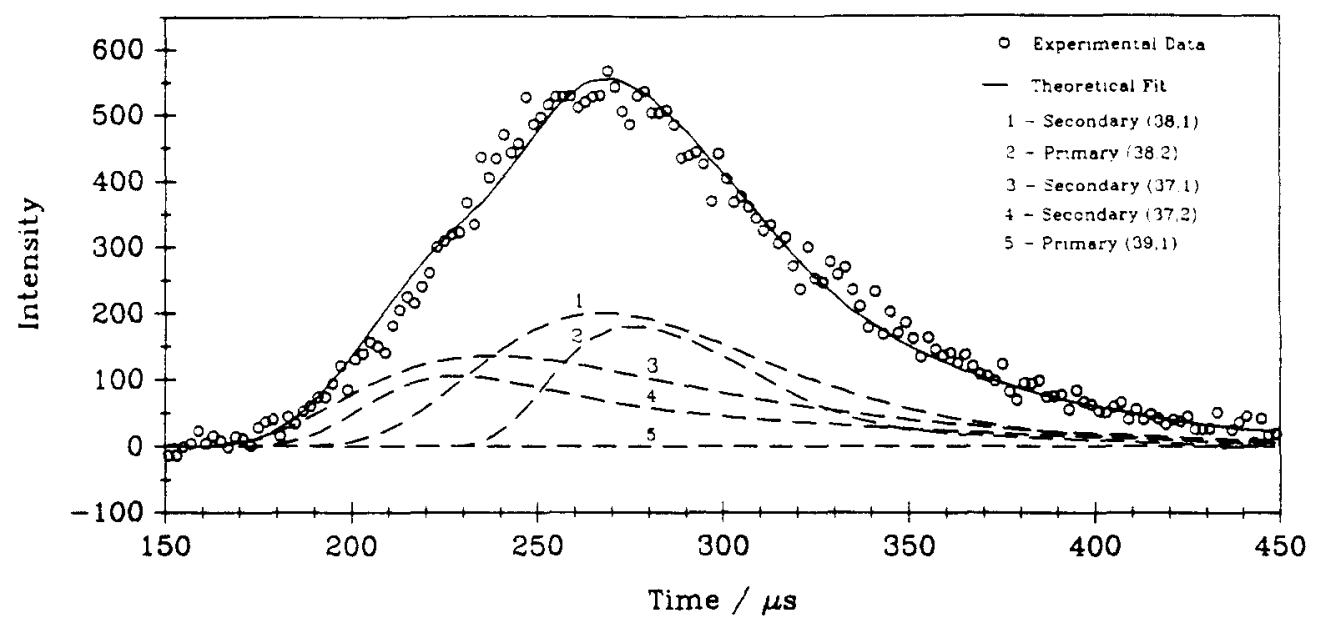

Figure 7. TOF spectrum from the 193.3-nm $\mathrm{C}_{3} \mathrm{H}_{4}$ photolysis. Five channels are needed for the fit: two primary and three secondary channels. 
Time of Flight Spectra for $\mathrm{m} / \mathrm{e}=36$ at $\theta=30^{\circ}$

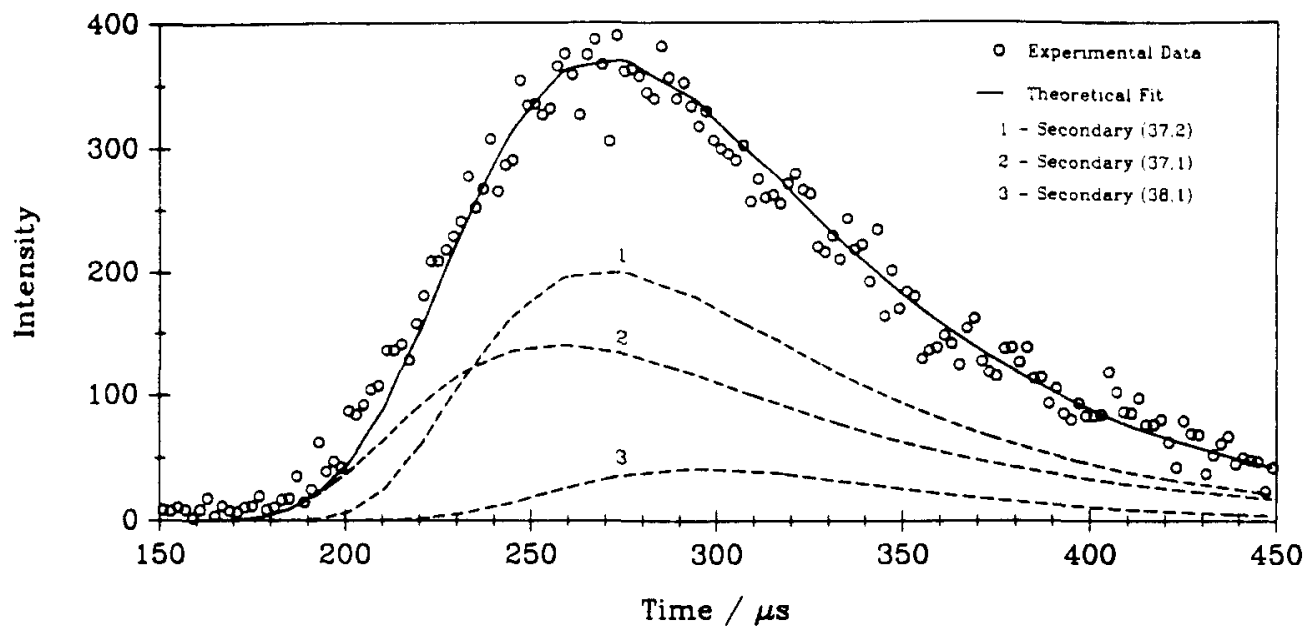

Figure 8. TOF spectrum from the 193.3-nm photolysis of allene. Four secondary channels are required to fit the data.

Time of Flight Spectra for $\mathrm{m} / \mathrm{e}=26$ at $\theta=20^{\circ}$

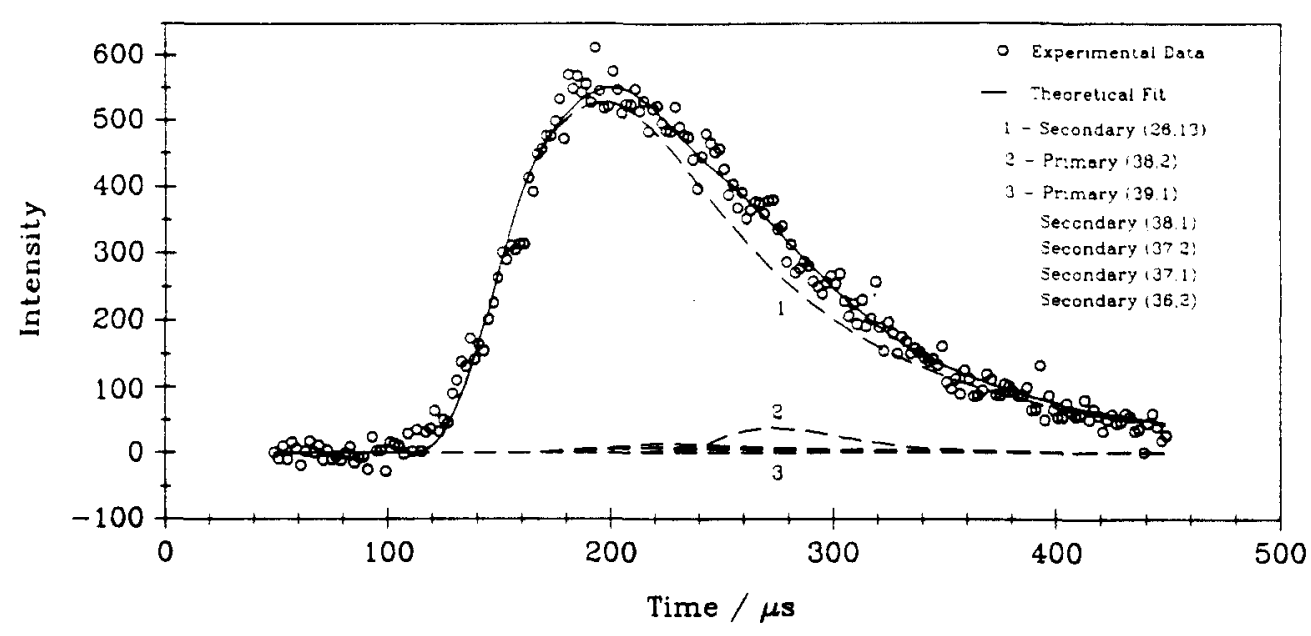

Figure 9. TOF spectrum from the photolysis of $\mathrm{C}_{3} \mathrm{H}_{4}$ at 193.3-nm. The principal channel that fits this data produces $\mathrm{CH}$ and $\mathrm{C}_{2} \mathrm{H}_{2}$ from $\mathrm{C}_{3} \mathrm{H}_{3}$. 


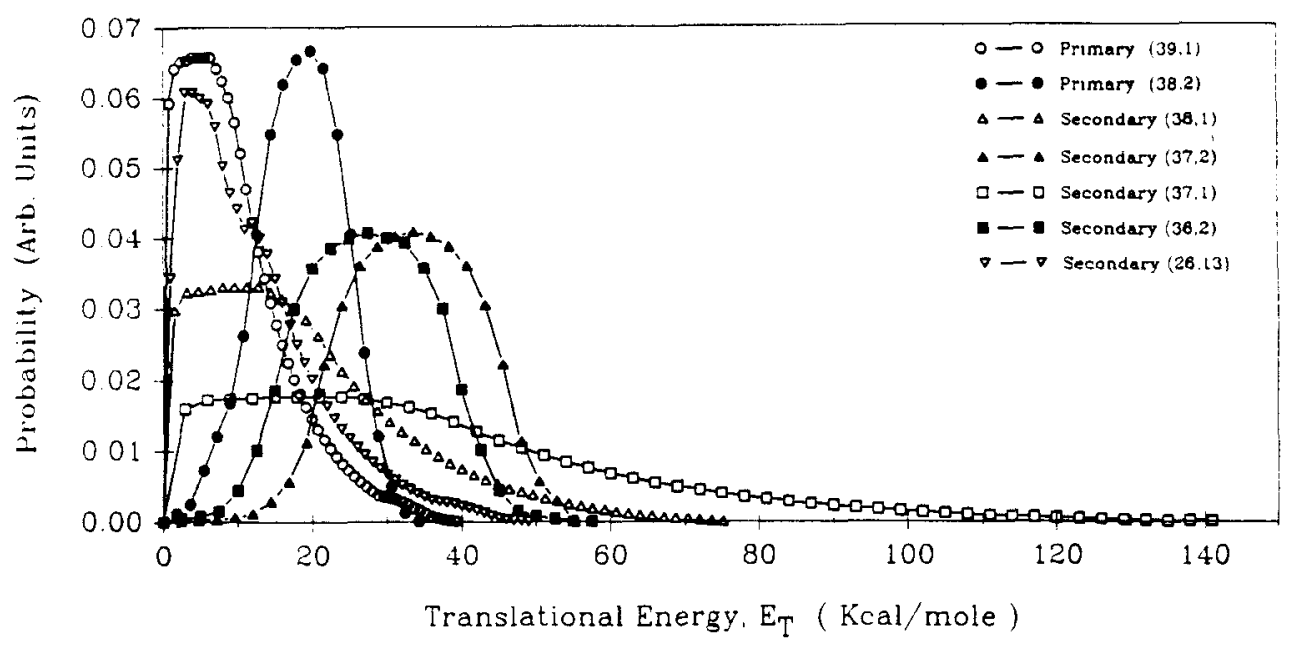

Figure 10. Translational energy distributions derived from fitting all of the data at all masses and angles.

reaction. These observations are all compatible with the earlier generalizations about energy distributions in photochemical reactions.

Reaction 3 is of particular interest to cometary science, since it suggests an alternate means of producing a $\mathrm{CH}$ radical in comets. Recent radio observations of the interstellar medium suggest that cyclopropenylidene $\left(\mathrm{C}_{3} \mathrm{H}_{2}\right)$ is widespread throughout the galaxy (Madden et al. 1989). Thus, it is not unreasonable to suppose that the cyclic $\mathrm{C}_{3} \mathrm{H}_{3}$ is also widely dispersed. It is thought that it is this cyclic version of the $\mathrm{C}_{3} \mathrm{H}_{3}$ radical that is being photolyzed in Reaction 3.

\subsection{PHOTOCHEMISTRY OF WATER}

The photochemistry of water has recently been reviewed by Crovisier (1989), and he has covered most of the published results. The detailed dynamics for the photodissociation in the first absorption continuum have been studied at $157 \mathrm{~nm}$ in great detail by Andresen and his colleagues (Andresen and Schinke 1987). From the structure in the absorption band and the theoretical potential energy curve, it is doubtful whether there will be surprises in the photochemistry in this region. One should be able to get a good idea about the energy partitioning in the fragments by using the theoretical curve and current theories for photodissociation. However, since even at this level, approximations have to be made in the theory, it is probably a good idea if the theoretical predictions are checked at another wavelength. This, of course, will require a laser at a wavelength between $180 \mathrm{~nm}$ and $140 \mathrm{~nm}$.

While the water photochemistry and the energy partitioning among the fragments are known in the first continuum, they have not been completely described at $121.6 \mathrm{~nm}$, which is the second most important photochemical region for $\mathrm{H}_{2} \mathrm{O}$ (Krautwald et al. 1986). 
It is known that the reaction channel leading to $\mathrm{OH}$ in the $\mathrm{A}^{2} \Sigma^{+}$state represents only about $10 \%$ of the total quantum yield. Recent measurements of the recoil velocity by determining the Doppler width of the laser-induced fluorescence of the recoiling $\mathrm{H}$ atom suggest the average kinetic energy in the $\mathrm{H}$ atom is $1.29 \pm 0.3 \mathrm{eV}$ (Krautwald 1986). This is the velocity of the $\mathrm{H}$ atom coming from the channel that produces $\mathrm{OH}\left(\mathrm{X}^{2} \Pi\right)$ state. The $\mathrm{H}$ atom associated with the $\mathrm{OH}\left(\mathrm{A}^{2} \Sigma^{+}\right)$has a much lower recoil velocity of $0.26 \mathrm{eV}$, which was not detected. Nevertheless, this gives us the information to analyze the hydrogen coma in comets. These results indicate that $\mathrm{OH}\left(\mathrm{X}^{2} \Pi\right)$ radical is produced highly rotationally excited and explains why it cannot be detected using LIF, since the higher rotational levels of the $\mathrm{A}^{2} \Sigma^{+}$are strongly predissociated and do not emit.

\subsection{PHOTOCHEMISTRY OF AMMONIA}

The photoionization TOF flight method for determining the energy partitioning has also been used by two groups to determine the energy partitioning in the photodissociation of $\mathrm{NH}_{3}$. These studies have been carried out by Wittig and his colleagues at $193 \mathrm{~nm}$ (Xu et al. 1989) and Welge and his colleagues (Biesner et al. 1988, 1989) at a variety of different wavelengths. Energy partitioning between the $\mathrm{H}$ atom and the $\mathrm{NH}_{2}$ radical is not simply described. Near-threshold tunneling occurs, and the internal energy distribution of the $\mathrm{NH}_{2}$ fragment reflects this. Changes occur when the $\mathrm{NH}_{3}$ molecule is excited to different vibrational and rotational levels of the excited state. However, as the photolysis energy increases, tunneling becomes less important, and the internal energy distribution is peaked at higher vibrational levels, in accord with our previous expectations for simple bond rupture.

Even though the $\mathrm{NH}_{2}$ radical absorbs and emits light in the visible region of the spectrum, LIF studies have not been very successful in determining the nascent internal energy after photolysis. The reason for this difficulty is that $\mathrm{NH}_{2}$ is produced with a large amount of internal energy as a result of the photodissociation process. Because of this, many different vibrational bands have to be measured over hundreds of angstroms, which requires many different dyes and very long scans. Quantitative results also require calibration of the detection system over this large wavelength range. Analysis is hence more complicated, so the TOF methods have a unique advantage for this particular molecule. This case illustrates in particular how many different techniques are necessary to completely unravel the photochemistry.

\section{5. $\mathrm{NH}_{2}$ PHOTOLYSIS AND THE FORMATION OF NH IN COMETS}

Many years ago, it was suggested that $\mathrm{NH}$ was formed in comets by the sequential photolysis of $\mathrm{NH}_{3}$ via the following type of mechanism (Jackson 1976):

$\begin{array}{lllll}\mathrm{NH}_{3}+ & \mathrm{hv} & \rightarrow & \mathrm{NH}_{2}+ & \mathrm{H} \\ \mathrm{NH}_{2}+ & \mathrm{hv} & \rightarrow & \mathrm{NH} & +\end{array}$

Recently, wavelength-resolved fluorescence studies using two $\mathrm{ArF}$ lasers at $193 \mathrm{~nm}$ have shown that this mechanism is correct at least for $\mathrm{NH}\left(\mathrm{A}^{3} \mathrm{I}\right)$ state radicals (Kenner et al. 1988). The researchers found that the lambda doublet population is preferentially populated in the antisymmetric lambda doublet. As discussed above, it is known that the 
$\mathrm{NH}_{2}$ radical is produced with considerable internal energy. The researchers point out that cold $\mathrm{NH}_{2}\left(\mathrm{X}^{2} \mathrm{~B}_{1}\right)$ should show different photodissociation dynamics. In this case, the alignment will be higher, the symmetric lambda doublet should be preferentially populated, and the rotational excitation will decrease as more energy appears in the translational degrees of freedom. These studies with cold $\mathrm{NH}_{2}$ have not been done, and it will be interesting to see if these predictions are correct when the studies are performed. The predictions do point out, however, the importance of carrying out photodissociation dynamics studies with cold free radicals, since these are the radicals that are expected to be present in the coma of comets and the dynamics can be dependent upon the internal energy of the radical.

The work on $\mathrm{NH}_{2}$ that has been reported thus far is for electronically excited $\mathrm{NH}$. It is important to determine if dissociation of this radical leads to ground-state $\mathrm{NH}$, and if it does, what the dynamics will be. Other questions will arise if ground-state $\mathrm{NH}$ is produced, such as "what is the branching ratio between the two channels as a function of wavelength?" and "if the dynamics are different between these two channels, do the dynamics change as the wavelengths change?" These are important questions that will have to be answered successfully to model the NH emission in comets.

\subsection{SH FORMATION AND DESTRUCTION}

There have been four recent results on the photochemistry of $\mathrm{H}_{2} \mathrm{~S}$, which is thought to be the parent of SH in comets (Continetti 1989, Weiner et al. 1989, Xie et al. 1989, Xu et al. 1989). Three of these studies used some type of time-of-flight technique, while the other used laser-induced fluorescence to measure the rotational population of the SH radical in the $\mathrm{v"}=0$ level. The TOF studies resolved the vibrational distribution of the SH and the spin orbit population of the SH radical. One of these TOF studies showed that the peak of the translational energy distribution decreases with decreasing amounts of available energy, but in all cases it is peaked away from zero (Kenner et al. 1988). This is unlike most radical elimination processes. The LIF study determined the rotational distribution at several different wavelengths, and the researchers found the average rotational energy decreases with decreasing energy (Xu et al. 1989). In both of these studies, a detailed model is presented to interpret the results. In one of the TOF studies, the laser fluence was high enough so that secondary photolysis of the $\mathrm{SH}$ radical was observed, but the data have yet to be analyzed.

\subsection{PHOTOCHEMISTRY OF HCN}

Radio observations of comets prove that $\mathrm{HCN}$ is present in comets (Huebner et al. 1974). In the solar radiation field, most of this HCN will be dissociated at Lyman alpha $(121.6 \mathrm{~nm})$ (Bockelee-Morvan and Crovisier 1985, Jackson 1973). The branching ratios for the three reactions that produce $C N$ in the $X^{2} \Sigma, A^{2} \Pi$, and $B^{2} \Sigma$ states have been determined from the TOF spectra of the $\mathrm{H}$ atom to be $0.43,0.45$, and 0.12 , respectively. The same spectra were used to determine the vibrational and rotational populations for the channel that produces $\mathrm{CN}$ in the $\mathrm{X}^{2} \Sigma$ state. The relative populations of the $\mathrm{v}^{\prime \prime}=0,1,2$, and 3 levels were found to be $1.0,0.6,0.3$, and 0.1 , respectively. The rotational population of the $\mathrm{v} "=0$ level peaks at $N^{\prime \prime}=40$ and decreases sharply on both sides of 
this peak. The vibrational and rotational distributions of the $A^{2} \Pi$ could not be unambiguously determined from the data.

\section{Conclusions}

Great progress has been made in understanding the photochemistry of some of the key stable molecules that are responsible for the radicals that are observed in comets. A variety of techniques have been used to determine the primary reaction products and the partitioning of energy among the fragments. In some cases, these studies need to be extended to molecules with the vibrational and rotational energy appropriate to comets, and in other cases, the effects of photolysis wavelength need to be carefully determined. No experimental technique appears to be completely satisfactory for obtaining all of the required data, but the $\mathrm{H}$-atom photoionization TOF method of K. Welge (Krautwald 1986, Krautwald et al. 1986) and the angular TOF method of Y.T. Lee (Wodtke and Lee 1987) both appear to be extremely powerful tools for cometary photochemistry.

The situation is less satisfactory for those radicals that are granddaughter species, which means they are formed by photodissociation of unstable free radicals. Even so, progress has been made in this sphere, with laboratory evidence for the formation of $\mathrm{C}_{2}$, $\mathrm{C}_{3}$, and $\mathrm{NH}$ from the secondary photolysis of $\mathrm{C}_{2} \mathrm{H}, \mathrm{C}_{3} \mathrm{H}_{2}$, and $\mathrm{NH}_{2}$. More work needs to be done with the photolysis of the cold precursor radicals at a variety of different wavelengths. Absorption spectra of the intermediate radicals at wavelengths where they dissociate are desperately needed to be able to evaluate the profiles of the granddaughter radicals.

Theoretical advances in photochemistry have also been made, and as these are put on firmer footing by comparisons with a body of experimental data, they will be more useful for cometary sciences. Already, the experimental and theoretical advances can probably adequately describe for comets the photochemistry of $\mathrm{H}_{2} \mathrm{O}$. Newer experimental techniques such as the Advanced Synchrotron light source, stronger VUV lasers based upon resonance sum frequency generation, and pulsed rare-gas dimer lasers will probably accelerate our knowledge of photochemistry and hence the chemistry of comets.

\section{Acknowledgments}

The author gratefully acknowledges the Guggenheim Foundation, the Miller Foundation, and the Planetary Atmospheres program of NASA under grant number NSG-903 for their support when this review was written. He also acknowledges Deon Anex, Barbara Balko, and Robert Continetti for their assistance in taking and analyzing the allene data and Y.T. Lee for his hospitality, encouragement, and advice during this time. The experimental LIF work on $\mathrm{C}_{2}$ was obtained by the author's graduate students Randy Urdahl and Yihan Bao. Last but not least, the author would like thank K. Welge and F. Sthul for their helpful discussions and the sharing of data about their experiments. 


\section{References}

Andresen, P., and Schinke, R. (1987). 'Dissociation of Water in the First Absorption Band: A Model System for Direct Photodissociation,' in Molecular Photodissociation Dynamics: Advances in Gas-Phase Photochemistry and Kinetics, M.N.R. Ashfold and J.E. Baggott (eds.), Royal Society of Chemistry, London, pp. 61-113.

Ashfold, M.N.R., and J.E. Baggott, eds. (1987). Molecular Photodissociation Dynamics: Advances in Gas-Phase Photochemistry and Kinetics, Royal Society of Chemistry, London.

Ashfold, M.N.R., M.T. Macpherson, and J.P. Simons (1979). 'Photochemistry and Spectroscopy of Simple Polyatomic-Molecules in the Vacuum Ultraviolet,' Topics in Current Chemistry, 86, 1-90.

Becker, K.H., D. Haaks, and M. Schurgers (1971). 'Fluorescence by the Vacuum-UV Photolysis of Acetylene,' Z. Naturforsch., A 26, 1770.

Biesner, J., L. Schnieder, J. Schmeer, G. Ahlers, X. Xie, K.H. Welge, M.N.R. Ashfold, and R.N. Dixon (1988). 'State Selective Photodissociation Dynamics of A State Ammonia. I,' J. Chem. Phys., 88, 3607-3616.

Biesner, J., L. Schnieder, G. Ahlers, X. Xie, K.H. Welge, M.N.R. Ashfold, and R.N. Dixon (1989). 'State Selective Photodissociation Dynamics of A State Ammonia. II,' to be submitted to J. Chem. Phys.

Bockelee-Morvan, D., and J. Crovisier (1985). 'Possible Parents for the Cometary CN Radical: Photochemistry and Excitation Conditions,' Astron. Astrophys., 151, 90100.

Buelow, S., M. Noble, G. Radhakrishnan, H. Reisler, C. Wittiz, and G. Hancock (1986). 'The Role of Initial Conditions in Elementary Gas-Phase Processes Involving Intermediate "Complexes",' J. Phys.Chem., 90, 1015-1027.

Cochran, A.L. (1985). 'C 2 Photolytic Processes in Cometary Comae,' Astrophys. J., 289, 388-391.

Continetti, R.E. (1989). Ph.D. Thesis, University of California.

Craig, B.B., W.L. Faust, and L.S. Goldberg (1982). 'UV Short Pulse Fragmentation of Isotopically Labeled Acetylene: Studies of Emission With Subnanosecond Resolutions,' J. Chem. Phys., 76, 5014-5021.

Crovisier, J. (1989). 'The Photodissociation of Water in Cometary Atmospheres,' Astron. Astrophys., 213, 459-464.

Delsemme, A.H. (1975). 'The Volatile Fraction of the Cometary Nucleus,' Icarus, 24, 95.

Fletcher, T.R., and S.R. Leone (1989). 'Photodissociation of $\mathrm{C}_{2} \mathrm{H}_{2}$ at $193 \mathrm{~nm}$ : Vibrational Distributions of the CCH Radical and the Rotational State Distribution of the A(101) State by Time-Resolved Fourier Transform Emission,' J. Chem. Phys., 90, $871-879$.

Gredel, R., E.F. van Dishoeck, and J.H. Black (1989). 'Fluorescent Vibration-Rotation Excitation of Cometary C2,' Astrophys. J., 338, 1047-1070.

Huebner, W.F., and C.W. Carpenter (1979). 'Solar Photo Rate Coefficients,' Rep. LA-8085-MS, Los Alamos Sci. Lab., Los Alamos, New Mexico.

Huebner, W.H., L.E. Snyder, and D. Buhl (1974). 'HCN Radio Emission From Comet Kohoutek (19737),' Icarus, 23, 580-584.

Jackson, W.M. (1973). 'Laser Induced Fluorescence of CN Radicals,' J. Chem. Phys., $59,960-961$. 
Jackson, W.M. (1976). 'The Photochemical Formation of Cometary Radicals,' J. Photochem., 5, 107-118.

Jackson, W.M. (1982). 'Laboratory Studies of Photochemistry,' in Comets, L.L. Wilkening (ed.), University of Arizona Press, Tucson, pp. 480-495.

Jackson, W.M., and R.J. Cody (1974). 'Laser Photoluminescence Spectroscopy of Photodissociation Fragments,' J. Chem. Phys., 61, 4183-4185.

Jackson, W.M., and H. Okabe (1986). 'Photodissociation Dynamics of Small Molecules,' in Advances in Photochemistry, D.H. Volman, G.S. Hammond, and K. Gollnick (eds.), John Wiley and Sons, New York, 13, pp. 1-94.

Jackson, W.M., J.B. Halpern, and C.S. Lin (1978). 'Multiphoton UV Photochemistry,' Chem. Phys. Lett., 55, 254.

Kenner, R.D., R.K. Browarzik and F. Sthul (1988). 'Two Photon Formation of $\mathrm{NH} / \mathrm{ND}\left(\mathrm{A}^{3} \pi\right)$ in the $193 \mathrm{~nm}$ Photolysis of Ammonia II. Photolysis of $\mathrm{NH}_{2}$,' J. Chem. Phys., 121, 457-471.

Krautwald, H.-J. (1986). 'Photodissoziationasdynamik einfacher Hydrid-Molekule im Vakuumultravioletten Spektralbereich,' Fakultat fur Physik Universitat Bielefeld.

Krautwald, H.-J., L. Schnieder, K. Welge, and M.N.R. Ashfold (1986). 'HydrogenAtom Photofragment Spectroscopy,' Faraday Discus. Chem. Soc., 82, 99-110.

Kresin, V.Z., and W.A. Lester, Jr. (1986). 'Quantum Theory of Polyatomic Photodissociation,' in Advances in Photochemistry, D.H. Volman, G.S. Hammond, and K. Gollnick (eds.), John Wiley and Sons, New York, 13, pp. 95-163.

Leone, S.R. (1982). 'Photofragment Dynamics,' in Advances in Chemical Physics, K.P. Lawley (ed.), John Wiley and Sons, Chichester, 50, p. 255.

Madden, S.C., W.M. Irvine, H.E. Matthews, P. Friberg, and D.A. Swade (1989). 'A Survey of Cyclopropenylidene $\left(\mathrm{C}_{3} \mathrm{H}_{2}\right)$ in Galactic Sources,' Astron. J., 97, 14031422.

Marsden, B.G. (1974). 'Comets,' Ann. Rev. of Astron. and Astrophys., 12, 1-21.

Matsumura, K., H. Kanamori, K. Kawaguchi, and E. Hirota (1988). 'Infrared Diode Laser Kinetic Spectroscopy of the $v_{3}$ Band of $C_{3}$,' J. Chem. Phys. 89, 3491-3494.

McDonald, J.R., A.P. Baronavski, and V.M. Donnelly (1978). 'Multiphoton VUV Laser Photodissociation of $\mathrm{C}_{2} \mathrm{H}_{2}$ : Emission From Electronically Excited Fragments,' Chem. Phys., 33, 161.

Mendis, D.A., and H.L.F. Houpis (1982). 'The Cometary Atmosphere and its Interaction With the Solar Wind,' Rev. of Geophys. and Space Phys., 20, 885-928.

O'Dell, C.R., R.R. Robinson, K.S.K. Swamy, P.J. McCarthy, and H. Spinard (1988). ' $\mathrm{C}_{2}$ in Comet Halley: Evidence for its Being Third Generation and Resolution of the Vibrational Population Discrepancy,' Astrophys. J., 334, 476-488.

Okabe, H. (1975). 'Photodissociation of $\mathrm{C}_{2} \mathrm{H}_{2}$ and $\mathrm{C}_{2} \mathrm{H} \mathrm{Br}$ in the VUV. Production of Electronic Excitation of $\mathrm{C}_{2} \mathrm{H}$ and $\mathrm{C}_{2}{ }^{1}$,' J. Chem. Phys., 62, 2782.

Okabe, H. (1978). Photochemistry of Small Molecules, John Wiley and Sons, New York.

Okabe, H., R.J. Cody, and J.E. Allen (1985). 'Laser Photolysis of $\mathrm{C}_{2} \mathrm{H}_{2}$ and $\mathrm{CF}_{3} \mathrm{C}_{2} \mathrm{H}$ at $193 \mathrm{~nm}$ : Production of $\mathrm{C}_{2}\left(\mathrm{~d}^{3} \Pi_{\mathrm{g}}\right)$ and $\mathrm{CH}\left(\mathrm{A}^{2} \Delta\right)$ and Their Quenching by Xe,' Chem. Phys., 92, 67.

Payne, W.A., and L.J. Stief (1972). 'Hydrogen Formation in the Photolysis of Propyne at $1236 \mathrm{~A}$,' J. Chem. Phys., 56, 3333-3336. 
Rabalais, J.W., J.M. McDonald, V. Scheer, and S.P. McGlynn (1971). 'Electronic Spectroscopy of Isoelectronic Molecules. II. Linear Triatomic Groups Containing Sixteen Valence Electrons,' Chem. Rev., 71, 73-108.

Royal Society of Chemistry (1986). Dynamics of Molecular Photofragmentation, Faraday Discussions of the Chemical Society, The Royal Society of Chemistry, London, Number 82.

Saito, Y., T. Hikida, T. Ichimura, and Y. Mori (1984). 'Fluorescence of Excited Ethynyl Radicals Produced by the Pulsed VUV Photolysis of $\mathrm{C}_{2} \mathrm{H}_{2}, \mathrm{C}_{2} \mathrm{D}_{2}$, and $\mathrm{C}_{2} \mathrm{HBr}$,' $\mathrm{J}$. Chem. Phys., 80, 31.

Sato, H. (1986). 'Photodissociation of Simple Molecules in the Gas Phase,' Research Reports of the Faculty of Engineering, Mie Univ., 11, 123-173.

Schinke, R. (1988). 'Rotational Distributions in Direct Molecular Photodissociation,' Ann. Rev. Phys. Chem., 39, 39-68.

Schinke, R. (1989a). 'Dynamics of Molecular Photodissociation,' in Collision Theory for Atoms and Molecules, F.A. Gianturco (ed.), Plenum, New York, pp. 229-285.

Schinke, R. (1989b). 'Rotational Excitation in Direct Photodissociation and its Relation to the Anisotropy of the Excited State Potential Energy Surface. How Realistic Is the Impulsive Model?', Comments, At. Mol. Phys., 23, 15-44.

Shiu, S., S.D. Peyerimhoff, and R.J. Bunker (1979). 'Calculated Potential Surfaces for the Description of the Emission Spectrum of the $\mathrm{C}_{2} \mathrm{H}$ Radical,' J. Molec. Spectr., 74, 124-135.

Shokoohi, F., T.A. Watson, H. Reisler, F. Kong, A.M. Renlund, and C. Wittig (1986). 'Photolytic Production of $\mathrm{C}_{2} \mathrm{H}$ : Collisional Quenching of $\mathrm{A}^{2} \Pi \rightarrow \mathrm{x}^{2} \Sigma^{+}$Infrared Emission and the Removal of Excited $\mathrm{C}_{2} \mathrm{H}$,' J. Phys. Chem., 90, 5695.

Stief, L.J., V.J. DeCarlo, and R.J. Mataloni (1965). 'Vacuum-Ultraviolet Photolysis of Acetylene,' J. Chem. Phys., 42, 3113-3121.

Urdahl, R.S., Yihan Bao, and W.M. Jackson (1988). 'Observation of the LIF Spectra of $\mathrm{C}_{2}\left(\mathrm{a}^{3} \Pi_{\mathrm{u}}\right)$ and $\mathrm{C}_{2}\left(\mathrm{a}^{1} \Pi_{\mathrm{u}}\right)$ From the Photolysis of $\mathrm{C}_{2} \mathrm{H}_{2}$ at $193 \mathrm{~nm}$,' Chem. Phys. Lett., $152,485-490$.

Weiner, B.R., H.B. Levine, J.J. Valentini and A.B. Baronavski (1989). 'Ultraviolet Photodissociation Dynamics of $\mathrm{H}_{2} \mathrm{~S}$ and $\mathrm{D}_{2} \mathrm{~S}$,' J. Chem. Phys., 90, 1403-1414.

Wodtke, A.M., and Y.T. Lee (1983). 'Photodissociation of Acetylene at 193.3-nm,' J. Phys. Chem., 85, 4744-4751.

Wodtke, A.M., and Y.T. Lee (1987). 'High Resolution Photofragmentation Translational Spectroscopy,' in Advances in Gas-Phase Photochemistry and Kinetics, Molecular Photodissociation Dynamics, M.N.R. Ashfold and J.E. Baggott (eds.), Royal Society of Chemistry, London, pp. 31-59.

Wurm, K. (1943). 'Die Natur der Kometen,' Mitt. Hamb. Sternwartz, 8, Nr, 51.

Xie, X., L. Schnieder, H. Wallmeir, U. Bottner, K.H. Welge, and M.N.R. Ashfold (1989). Photodissociation Dynamics of $\mathrm{H}_{2} \mathrm{~S}\left(\mathrm{D}_{2} \mathrm{~S}\right)$ Following Excitation Within its First Continuum,' submitted to J. Chem. Phys.

Xu, Z., B. Koplitz and C. Wittig (1989). 'Velocity-Aligned Doppler Spectroscopy,' J. Chem. Phys., 90, 2692-2702.

Yamamoto, T. (1981). 'On the Photochemical Formation of $\mathrm{CN}, \mathrm{C}_{2}$, and $\mathrm{C}_{3}$ Radicals in Cometary Comae,' The Moon and the Planets, 24, 453-463.

Zhao, X. (1988). 'Photodissociation of Cyclic Compounds in a Molecular Beam,' Lawrence Berkeley Laboratory Report, LBL-26332, Berkeley, California. 